\title{
Anti-Inflammatory and Organ-Protective Effects of Resveratrol in Trauma-Hemorrhagic Injury
}

\author{
Fu-Chao Liu, ${ }^{1,2,3}$ Yung-Fong Tsai, ${ }^{1,2,3}$ Hsin-I Tsai, ${ }^{1,2,3}$ and Huang-Ping Yu ${ }^{1,2}$ \\ ${ }^{1}$ Department of Anesthesiology, Chang Gung Memorial Hospital, Taoyuan City 333, Taiwan \\ ${ }^{2}$ College of Medicine, Chang Gung University, Taoyuan City 333, Taiwan \\ ${ }^{3}$ Graduate Institute of Clinical Medical Sciences, Chang Gung University, Taoyuan City 333, Taiwan \\ Correspondence should be addressed to Huang-Ping Yu; yuhp2001@adm.cgmh.org.tw
}

Received 3 October 2014; Accepted 4 December 2014

Academic Editor: Zhengyuan Xia

Copyright (C) $2015 \mathrm{Fu}$-Chao Liu et al. This is an open access article distributed under the Creative Commons Attribution License, which permits unrestricted use, distribution, and reproduction in any medium, provided the original work is properly cited.

\begin{abstract}
Resveratrol, a natural polyphenolic compound of grape and red wine, owns potential anti-inflammatory effects, which results in the reduction of cytokines overproduction, the inhibition of neutrophil activity, and the alteration of adhesion molecules expression. Resveratrol also possesses antioxidant, anti-coagulation and anti-aging properties, and it may control of cell cycle and apoptosis. Resveratrol has been shown to reduce organ damage following traumatic and shock-like states. Such protective phenomenon is reported to be implicated in a variety of intracellular signaling pathways including the activation of estrogen receptor, the regulation of the sirtuin 1/nuclear factor-kappa B and mitogen-activated protein kinases/hemeoxygenase-1 pathway, and the mediation of proinflammatory cytokines and reactive oxygen species formation and reaction. In the recent studies, resveratrol attenuates hepatocyte injury and improves cardiac contractility due to reduction of proinflammatory mediator expression and ameliorates hypoxia-induced liver and kidney mitochondrial dysfunction following trauma and hemorrhagic injuries. Moreover, through antiinflammatory effects and antioxidant properties, the resveratrol is believed to protect organ function in trauma-hemorrhagic injury. In this review, the organ-protective and anti-inflammatory effects of resveratrol in trauma-hemorrhagic injury will be discussed.
\end{abstract}

\section{Introduction}

Resveratrol is a naturally occurring plant antibiotic known as phytoalexins, found in various plants and fruits, especially abundant in grapes and red wine $[1,2]$. Previous reports have demonstrated the protective effects of resveratrol in different pathological conditions and experimental models [3-7]. Many clinical studies also indicated the beneficial effects of resveratrol in human diseases [8-13]. A growing body of evidence showed that resveratrol might play potential therapeutic roles in human health by its antiinflammatory, antioxidant, antiaging, antidiabetic, anticoagulative, and apoptotic properties [1, 7, 14, 15]. Resveratrol attenuates organ injury in trauma-hemorrhagic (T-H) injury through multiple pathways, in which a number of the molecular targets and protective effects of resveratrol have been identified, including the estrogen receptors (ER) $[16,17]$, the protein kinase $\mathrm{B}(\mathrm{Akt})$, the AMP-activated protein kinase
(AMPK) $[18,19]$, the hemeoxygenase-1 (HO-1) [20-22], the histone/protein deacetylase sirtuin 1 (SIRT1) [23, 24], and nuclear factor-kappa B (NF- $\kappa$ B) $[25,26]$ (Figure 1).

A variety of laboratory and clinical researches also show that resveratrol may lead to tissue- and organ-protective effects against various injuries [27-33]. Traumatic injury is recognized to induce the excessive production of oxidants and proinflammatory mediators and subsequent development of multiple organ dysfunctions [34-37] and resveratrol has been suggested to have organ-protective effect on trauma and hemorrhagic injuries due to its antioxidative activities and anti-inflammatory effects [18, 20, 38-42]. Trauma-hemorrhagic injury causes excessive production of proinflammatory mediators, cytokines, and chemokines. The enhanced secretion of proinflammatory cytokines is a critical factor in the initiation and perpetuation of organ injury [39, $43,44]$. These cytokines recruit other immune cells including neutrophils, thereby increasing leukocyte activation and 


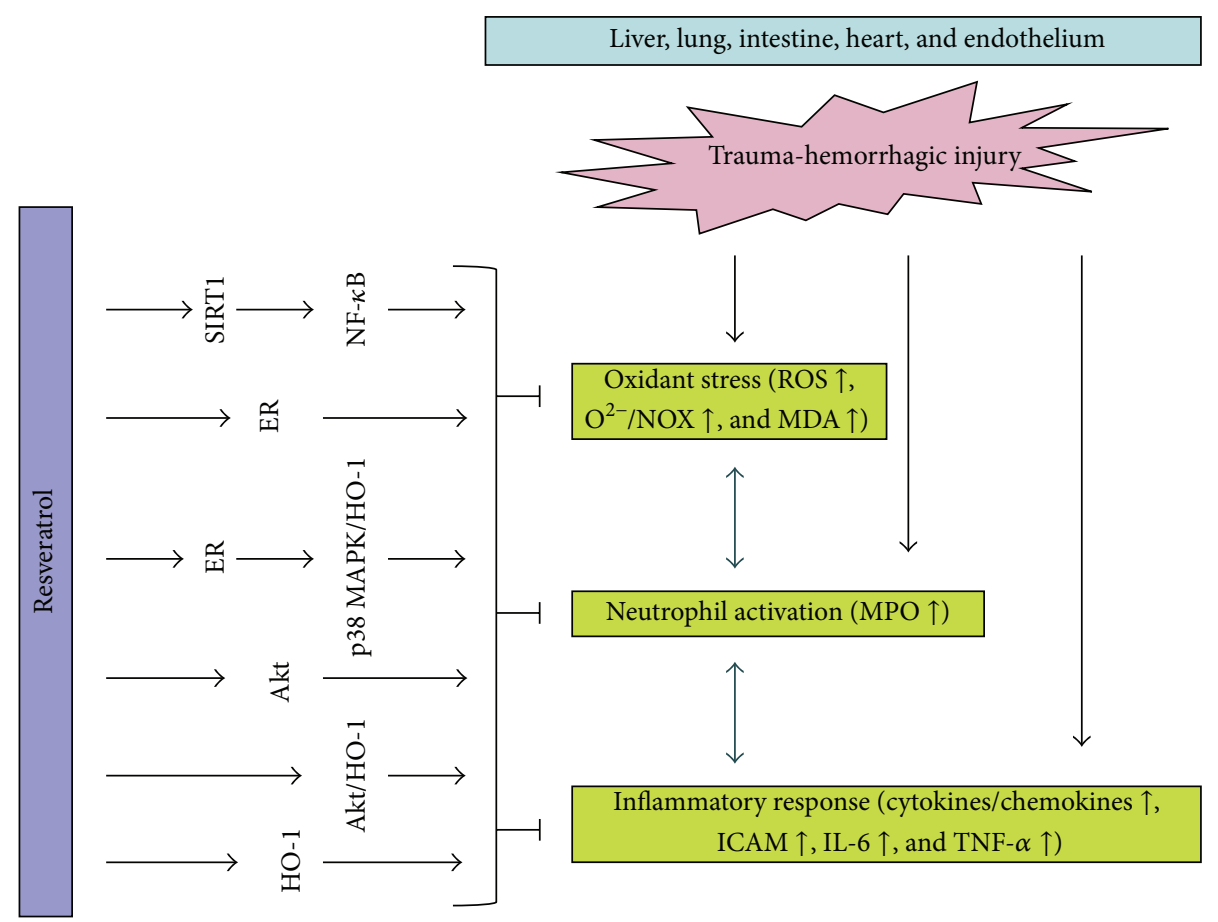

FIGURE 1: The anti-inflammatory and protective pathways of resveratrol in trauma-hemorrhagic injury. ER: estrogen receptor; SIRT1: sirtuin 1; HO-1: hemeoxygenase-1; p38 MAPK: p38 mitogen-activated protein kinase; NF- $\kappa$ B: nuclear factor-kappa B; ROS: reactive oxygen species; MDA: malondialdehyde; NOX: NADPH oxidase; MPO: myeloperoxidase; ICAM: intercellular adhesion molecule; IL-6: interleukin 6.

trafficking result in organ injury [45-47]. In this review, we summarize the protective effects and possible mechanisms of resveratrol on the preservation of organ function in $\mathrm{T}-\mathrm{H}$ injury (Table 1).

\section{The Pulmonary Protective Effect of Resveratrol in T-H Injury}

The activation of neutrophils in T-H injury [39, 47-49] and pulmonary injury is associated with an increased neutrophil accumulation [40, 42]. Neutrophils leave the microcirculation and migrate to matrix proteins or other cells and release mediators, which diffuse across the endothelium and hurt parenchymal cells $[46,47]$. The intercellular adhesion molecule 1 (ICAM-1), constitutively present on the surface of endothelial cells, enhances firm adhesion of neutrophils to the vascular endothelium and is markedly upregulated following T-H injury [40, 47, 50]. For example, pulmonary ICAM-1 expression is increased in the lung in T-H shock $[40,47,51]$. The activated neutrophils appear to infiltrate the injured lung in parallel with increased expression of adhesion molecules on endothelial cells and also lead to the elevation of local chemokines/cytokines [40, 47, 51]. Chemotaxis has an important functional response to chemokines and is a key event in the recruitment of neutrophils in inflammation. Cytokine-induced neutrophil chemoattractant 1 (CINC1) and CINC-3 are members of the IL- 8 family and are potent chemoattractants for neutrophils $[39,42]$. Moreover, the levels of the CINC-1 and CINC-3 are elevated in T-H injury. Furthermore, convincing evidence has shown that interleukin 6 (IL-6) plays an important role in organ injuries and is required for the expression of adhesion molecules and release of chemokines [52-54]. IL-6-deficient mice show less neutrophils infiltration and organ damage as compared with wild-type mice under hemorrhagic shock [54]. IL-6 could be released from macrophages and lymphocytes and appears to be an essential component of the inflammatory cascade that is associated with organ damage in T-H injury $[51,55]$.

Resveratrol has a protective role in organ damage following T-H injury via the reduction of neutrophil accumulation $[46,47,49]$. The role of resveratrol in the attenuation of lung injury is likely due to the reduction of chemokines in $\mathrm{T}$ $\mathrm{H}$ injury $[40,42,51]$. IL-6, a critical early mediator in the lung during $\mathrm{T}-\mathrm{H}$ injury, is inhibited by resveratrol treatment $[42,51]$. The ability of resveratrol to modulate the expression of inflammatory cytokines, adhesion molecules, and chemokines suggests a role for resveratrol in the regulation of lung inflammation.

\section{The Liver Protective Effect of Resveratrol in T-H Injury}

The liver is considered to be a critical organ in the development of delayed organ dysfunction in patients having traumatic injuries and hemorrhagic shock $[37,39,45,56]$. T$\mathrm{H}$ injury results in massive production of proinflammatory mediators (IL-6, ICAM-1, CINC-1, and CINC-3) and the subsequent accumulation of neutrophils in the injured liver $[39,41,47,48]$. Resveratrol reduces cytokine production and 
TABLE 1: The organ-protective effects and mechanisms of resveratrol in trauma-hemorrhagic injury.

\begin{tabular}{|c|c|c|c|c|}
\hline Species & Target organ & Effective dose & Effects and mechanisms & Ref. \\
\hline Sprague-Dawley rat & Liver & $30 \mathrm{mg} / \mathrm{kg} / \mathrm{BW}$ & $\begin{array}{c}\text { Estrogen receptor-dependent HO-1 } \\
\text { expression } \uparrow\end{array}$ & [20] \\
\hline Sprague-Dawley rat & Liver & $30 \mathrm{mg} / \mathrm{kg} / \mathrm{BW}$ & 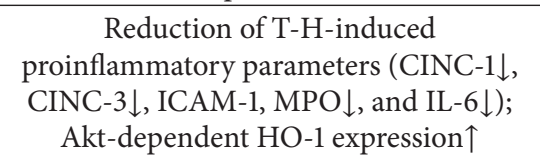 & [39] \\
\hline Sprague-Dawley rat & Liver & $30 \mathrm{mg} / \mathrm{kg} / \mathrm{BW}$ & $\begin{array}{c}\text { Reduction of T-H-induced } \\
\text { proinflammatory parameters (CINC-1 } 1 \text {, } \\
\text { CINC-3 } \downarrow \text {, ICAM-1, MPO } \downarrow \text {, and IL-6 } \downarrow \text { ); } \\
\text { estrogen receptor-mediated pathway }\end{array}$ & [41] \\
\hline Sprague-Dawley rat & Liver & $30 \mathrm{mg} / \mathrm{kg} / \mathrm{BW}$ & $\begin{array}{l}\text { Reduction of T-H-induced mitochondria } \\
\text { damage and hepatocyte injury; increase } \\
\text { in SIRT1 expression; and decrease in p53 } \\
\text { and NF- } \kappa \text { B activity; IL- } 6 \downarrow \text {, MDA } \downarrow\end{array}$ & [73] \\
\hline Sprague-Dawley rat & Lung & $30 \mathrm{mg} / \mathrm{kg} / \mathrm{BW}$ & $\begin{array}{c}\text { Reduction of T-H-induced } \\
\text { proinflammatory parameters (CINC-1 } 1 \text {, } \\
\text { CINC-3 } \downarrow \text {, ICAM-1, MPO } \downarrow \text {, and IL-6 } \downarrow \text { ) }\end{array}$ & [40] \\
\hline Sprague-Dawley rat & Lung & $30 \mathrm{mg} / \mathrm{kg} / \mathrm{BW}$ & $\begin{array}{c}\text { Estrogen receptor-dependent HO-1 } \\
\text { expression } \uparrow\end{array}$ & [20] \\
\hline Sprague-Dawley rat & Intestine & $30 \mathrm{mg} / \mathrm{kg} / \mathrm{BW}$ & $\begin{array}{c}\text { Reduction of T-H-induced } \\
\text { proinflammatory parameters (CINC- } 1 \downarrow \text {, } \\
\text { CINC-3 } \downarrow \text {, ICAM-1, MPO } \downarrow \text {, IL-6 } \downarrow \text {, and } \\
\text { TNF- } \alpha \downarrow \text { ); estrogen receptor-dependent } \\
\text { P38/HO- } 1 \text { expression } \uparrow\end{array}$ & [18] \\
\hline Sprague-Dawley rat & Heart & $8 \mathrm{mg} / \mathrm{kg} / \mathrm{BW}$ & $\begin{array}{c}\text { Reduction of T-H-induced left } \\
\text { ventricular contractility impairment } \\
\text { through elevated SIRT1 expression; } \\
\text { cardiac ATP } \downarrow \text {, cytosolic cytochrome C } \downarrow \text {, } \\
\text { and plasma TNF- } \alpha \downarrow\end{array}$ & [86] \\
\hline Sprague-Dawley rat & Heart & Not available & $\begin{array}{l}\text { Reduction of T-H-induced mitochondria } \\
\text { damage and improving left ventricular } \\
\text { function through restored SIRT1 activity } \\
\text { and PDK1 expression }\end{array}$ & [94] \\
\hline Sprague-Dawley rat & Heart & $30 \mathrm{mg} / \mathrm{kg} / \mathrm{BW}$ & $\begin{array}{c}\text { Reduction of T-H-induced } \\
\text { proinflammatory parameters (ICAM- } 1 \downarrow \text {, } \\
\text { MPO } \downarrow \text {, and IL-6 } \downarrow \text { ); reduction of } \\
\text { T-H-induced cardiac injury through } \\
\text { elevated p-Akt activity }\end{array}$ & [38] \\
\hline Sprague-Dawley rat & Endothelium & $30 \mathrm{mg} / \mathrm{kg} / \mathrm{BW}$ & $\begin{array}{c}\text { Acetylcholine-induced } \\
\text { endothelium-dependent relaxation } \downarrow \\
\text { through estrogen receptor-dependent } \\
\text { pathway; ROS radical/NADPH oxidase } \\
\text { expression } \downarrow\end{array}$ & [20] \\
\hline Sprague-Dawley rat & Aorta & $30 \mathrm{mg} / \mathrm{kg} / \mathrm{BW}$ & $\begin{array}{c}\text { NADPH-stimulated ROS } \downarrow \text {; aortic } \\
\text { p22phox, p47phox, gp91phox, NOX1, and } \\
\text { NOX4 mRNA levels } \downarrow\end{array}$ & {$[20]$} \\
\hline
\end{tabular}

Note: the species (Sprague-Dawley rat) are all the same in Table 1.

BW: body weight; ER: estrogen receptor; HO-1: hemeoxygenase-1; SIRT1: sirtuin 1; NF- $\kappa$ B: nuclear factor-kappa B; MDA: malondialdehyde; TNF- $\alpha$ : tumor necrosis factor-alpha; CINC-1: cytokine-induced neutrophil chemoattractant 1; ICAM-1: intercellular adhesion molecule 1; MPO: myeloperoxidase; IL-6: interleukin 6; ROS: reactive oxygen species; NOX: NADPH oxidase; PDK1: pyruvate dehydrogenase kinase 1.

neutrophil accumulation in a rodent model of LPS-induced hepatic oxidative stress and inflammation [57].

Resveratrol binds to ER- $\alpha$ and ER- $\beta$ and therefore alters the transcriptional activity of estrogen-responsive target genes $[17,19,58,59]$. Resveratrol could modulate TNF- $\alpha$ genes expression and suppress IL-6 transcription via an ER$\alpha$ signal integration [16]. Other studies demonstrated the role of sexual dimorphism in response to injury and showed the importance of sex steroids on the maintenance of organ function in T-H injury $[45,47,60,61]$. The administration of 
resveratrol in combination with an ER antagonist ICI 182,780 blocks the hepatoprotective effect and such ER pathway is critical in hepatoprotection in T-H injury [41]. Building on these findings, ER pathways may be potentially useful therapies in the treatment of trauma patients $[41,62,63]$. In addition, estrogen treatment upregulates phosphatidylinositol 3-kinase (PI3K)/Akt expression via an estrogen receptor following T-H injury [64].

HO-1, a stress-inducible heme-degrading enzyme, provides cytoprotection against oxidative stress and inflammatory reaction $[65,66]$. HO-1 expression is upregulated during T-H injury, and its induction appears to play a central role in the preservation of organ microcirculation under such conditions $[67,68]$. A growing body of evidence demonstrates that Akt activation induces $\mathrm{HO}-1$, which is known to have a protective effect in many organs under various deleterious conditions, including $\mathrm{T}-\mathrm{H}$ injury [39, $42,68,69]$. The upregulation of $\mathrm{HO}-1$ causes a reduction of chemokines, cytokines, and adhesion molecules. It also decreases neutrophil accumulation and ameliorates organ injury in trauma-related shock status $[39,42,70]$. The administration of $17 \beta$-estradiol or flutamide (an antiandrogen drug) in $\mathrm{T}-\mathrm{H}$ injury increases $\mathrm{HO}-1$ expression, which attenuates the organs' dysfunction and injury [67-69]. The PI3K/Akt is an important signaling pathway controlling endogenous negative feedback or compensatory mechanism, in which proinflammation and chemotactic events are limited in response to injury $[37,39,64]$. Activation of PI3K/Akt signaling cascade by resveratrol has been observed in different tissues [38, 39, $71,72]$. Resveratrol-mediated increase in $\mathrm{HO}-1$ is found to be Akt-dependent. When resveratrol is coadministered with $\mathrm{PI} 3 \mathrm{~K} / \mathrm{Akt}$ antagonist, it abolishes the resveratrol-mediated HO-1 increase and hepatic protective effects in T-H injury $[39,70]$. These results indicate that resveratrol attenuated liver damage and decreased proinflammatory mediator expression in $\mathrm{T}-\mathrm{H}$ injury, likely through Akt-dependent $\mathrm{HO}-1$ pathway $[39,70]$.

In addition, Powell et al. demonstrated that resveratrol could reduce $\mathrm{T}-\mathrm{H}$ injury-induced mitochondria damage and hepatocyte injury. Resveratrol illustrates a protective effect through an increase in SIRT1 expression and a decrease in p53 and NF- $\kappa$ B activity. It also inhibits proinflammatory mediator IL-6 and lipoperoxidation MDA expression [73].

\section{The Intestinal Protective Effect of Resveratrol in T-H Injury}

Intestinal tract is highly sensitive to injury. T-H injury could induce oxidants release, leading to microvascular permeability change, interstitial edema, mucosal barrier dysfunction, and inflammatory cell infiltration. ER also plays a pivotal role in intestinal injury after T-H shock. Previous reports showed that ER leads to the induction of p38 MAPK $[18,47$, $74,75]$, which contributes to the protection of cell/tissue in response to a variety of stimuli [76-78]. Estrogen-mediated anti-inflammatory and organ-protective effects are abolished by the administration of a p38 MAPK inhibitor SB-203580 following T-H injury $[18,75]$.
P38 MAPK activation regulates mucosal recovery in ischemic-injured porcine ileum [79] and protects glomerular epithelial cells against complement-mediated cell injury [80]. The p38 MAPK phosphorylation contributes to intestineprotection in $\mathrm{T}-\mathrm{H}$ injury after ischemic preconditioning or T-H $[18,47,74,75]$. Resveratrol also reduces chronic colonic inflammation [81] and protects $\mathrm{H}_{2} \mathrm{O}_{2}$-treated embryonic rat heart $\mathrm{H} 9 \mathrm{c} 2$ cells via the p38 MAPK pathway [82].

The upregulation of $\mathrm{HO}-1$ is known for its protective role in cellular stress during inflammation, ischemia, and radiation, as well as the anti-inflammatory and antiapoptotic effects. Resveratrol protects the intestinal epithelial barrier function against TNF- $\alpha$ and oxidative stress through upregulation of HO-1 expression in intestinal ischemia/reperfusion injury [83]. p38 MAPK activation induces HO-1 expression and maintains organ function under various stresses and injuries. Recent studies indicate that the treatment of animals with SB-203580, which blocks p38 MAPK, abolishes resveratrol-induced upregulation of $\mathrm{HO}-1$ after T-H $[18,75]$. These findings indicate that the salutary effects of resveratrolmediated attenuation of intestinal injury in T-H are mediated, at least in part, through ER-dependent p38 MAPK/HO-1 upregulation.

\section{The Cardioprotective Effect of Resveratrol in T-H Injury}

Resveratrol has been shown to possess cardioprotective effects during ischemia-reperfusion injury $[84,85]$ and decreases organ injury in T-H injury $[38,86]$. Cardiac injury is associated with increased neutrophil accumulation $[38,47]$ and such in small intestine is correlated with the attenuation of trauma-hemorrhage-induced cardiac dysfunction [18].

Activation of the PI3K pathway protects cells or organs against hypoxia and ischemia-reperfusion injury via inhibition of the apoptosis machinery [87, 88]. Modulation of the PI3K/Akt pathway with the PI3K inhibitor wortmannin suppresses coagulation and inflammation and decreases the survival of mice subjected to sepsis [89]. PI3K/Akt pathway also mediates neutrophils activation and regulates leukocyte signaling and function, to undergo chemotaxis [90]. Resveratrol decreases the production of proinflammatory mediators and ameliorates cardiac injury in T-H injury [38]. Blockade of Akt activation abolishes the salutary effects of resveratrol in the heart following T-H [38]. Altogether, resveratrol-related cardioprotective effect is likely mediated through an Aktdependent pathway in T-H injury [38].

SIRT1 has been shown to regulate the mammalian genes transcription and silence the tumor suppressor genes [91, 92]. The SIRT1 transcription-modulating proteins demonstrate a fine balance in response to intracellular stimulus, such as hypoxia or stress signals. The beneficial effects of resveratrol mediated by SIRT1 activation can be contributed by different organs $[24,86,93,94]$. Resveratrol improves heart function following $\mathrm{T}-\mathrm{H}$ injury by downregulating SIRT1 expression [86]. The protective effect of resveratrol on left ventricular contractility and systemic TNF- $\alpha$ levels is abolished by sirtinol (a SIRT1 inhibitor) [86]. In addition, Jian et al. 
indicated that SIRT1 enzyme activity is decreased following T-H injury [94]. SIRT1 modulates left ventricular function in T-H injury through regulation of cellular energetic. The results suggest that the reduced SIRT1 levels in T-H injury may be related to declining mitochondrial function [94].

\section{The Endothelial Protective Effect of Resveratrol in T-H Injury}

Oxidative stress and superoxide radical generation are believed to contribute to the pathogenesis of endothelial dysfunction in low-flow states [95-97], resulting in inadequate tissue perfusion $[96,97]$.

Endothelial nicotinamide adenine dinucleotide phosphate-oxidase (NOX) is an important source of reactive oxygen species (ROS) of the vasculature, and, under various stressful conditions, a significant increase in NOX-generated ROS by the endothelium has been observed [95, 98]. Elevated ROS is a critical contributing factor to endothelial dysfunction, and antioxidants have been demonstrated to reduce ROS-induced injuries [95, 98]. Resveratrol has broad antioxidant and anti-inflammatory activities in a number of biological reactions $[15,99,100]$, for instance, cardiovascular beneficial effects on atherosclerosis, ventricular arrhythmia, and myocardial ischemia-reperfusion I/R injury [101, 102]. Resveratrol's cardioprotective effects in I/R injury are achieved through its ROS-scavenging activity [77, 103]. However, the cardiovascular benefit of resveratrol may not simply be attributable to its antioxidant effect. Recent findings show that resveratrol reduces NOX activity in rat aortic endothelial cells and macrophages $[20,104,105]$. Resveratrol prevents T$\mathrm{H}$ injury-induced oxidative stress and protects endothelium from subsequent oxidative functional damages [20]. The beneficial effects include inhibition of the NOX activity and direct scavenging of ROS. The protective effects of resveratrol are likely through suppression of the NOX enzyme complex activity in the cell membrane and the cytosol, including decreased membrane-bound proteins p22phox and gp91phox and cytosolic protein p47phox [20].

$\mathrm{HO}-1$ appears to act as a protective agent in many organs against insults, such as trauma, ischemia, and oxidative stress $[67,106,107]$. Estrogen or flutamide enhances HO1 expression, and resveratrol can modulate $\mathrm{HO}-1$ induction via ER-related pathway $[18,20]$. The upregulation in $\mathrm{HO}-1$ is associated with the prevention of endothelial dysfunction and the salutary effects of resveratrol on endothelial function are mediated in part by upregulation of the HO-1-related pathway via ER [20].

\section{Conclusions}

Resveratrol has been shown to possess the beneficial effects in various studies and experimental conditions. There is increasing evidence that resveratrol maintains organ function after trauma or shock-like states. Resveratrol can attenuate organs injury in $\mathrm{T}-\mathrm{H}$ injury through multiple pathways. However, the protective benefits of resveratrol may not simply be attributed to its anti-inflammatory or antioxidant effect.
It is implicated that resveratrol is also mediated in part via a variety of intracellular signaling pathways, including the regulation of the HO-1/MAPK, PI3K/Akt, ER, and SIRT1. This complex network needs additional elucidation in future experimental studies and clinical trials.

$\begin{array}{ll}\text { Abbreviations } \\ \text { T-H: } & \text { Trauma-hemorrhage } \\ \text { ER: } & \text { Estrogen receptor } \\ \text { SIRT1: } & \text { Sirtuin 1 } \\ \text { HO-1: } & \text { Hemeoxygenase-1 } \\ \text { p38 MAPK: } & \text { p38 mitogen-activated protein kinase } \\ \text { PI3K: } & \text { Phosphatidylinositol 3-kinase } \\ \text { Akt: } & \text { Protein kinase B } \\ \text { NF- } \kappa \text { B: } & \text { Nuclear factor-kappa B } \\ \text { ROS: } & \text { Reactive oxygen species } \\ \text { MDA: } & \text { Malondialdehyde } \\ \text { NOX: } & \text { NADPH oxidase } \\ \text { MPO: } & \text { Myeloperoxidase } \\ \text { CINC-1: } & \text { Cytokine-induced neutrophil } \\ & \text { chemoattractant 1 } \\ \text { ICAM-1: } & \text { Intercellular adhesion molecule 1 } \\ \text { IL-6: } & \text { Interleukin 6 } \\ \text { TNF- } \alpha: & \text { Tumor necrosis factor-alpha } \\ \text { PDK1: } & \text { Pyruvate dehydrogenase kinase 1. }\end{array}$

\section{Conflict of Interests}

The authors declare that there is no conflict of interests regarding the publication of this paper.

\section{Acknowledgments}

This work was partially supported by grants from the National Science Council (NSC102-2314-B-182A-051-MY3) and Chang Gung Memorial Hospital (CMRPG3B1052 and CMRPG3B1053) to Huang-Ping Yu. Support was also provided by the National Science Council (NSC103-2314B-182-046-MY2) and Chang Gung Memorial Hospital (CMRPG3B1623) to Fu-Chao Liu.

\section{References}

[1] W. Yu, Y. C. Fu, and W. Wang, "Cellular and molecular effects of resveratrol in health and disease," Journal of Cellular Biochemistry, vol. 113, no. 3, pp. 752-759, 2012.

[2] L. M. Chu, A. D. Lassaletta, M. P. Robich, and F. W. Sellke, "Resveratrol in the prevention and treatment of coronary artery disease," Current Atherosclerosis Reports, vol. 13, no. 6, pp. 439446, 2011.

[3] S. M. Hamza and J. R. B. Dyck, "Systemic and renal oxidative stress in the pathogenesis of hypertension: modulation of longterm control of arterial blood pressure by resveratrol," Frontiers in Physiology, vol. 5, article 292, 2014.

[4] L. Song, L. Chen, X. Zhang, J. Li, and W. Le, "Resveratrol ameliorates motor neuron degeneration and improves survival in SOD1 ${ }^{\mathrm{G} 93 \mathrm{~A}}$ mouse model of amyotrophic lateral sclerosis," 
BioMed Research International, vol. 2014, Article ID 483501, 10 pages, 201.

[5] S. Yavuz, N. E. Aydin, O. Celik, E. Yilmaz, E. Ozerol, and K. Tanbek, "Resveratrol successfully treats experimental endometriosis through modulation of oxidative stress and lipid peroxidation," Journal of Cancer Research and Therapeutics, vol. 10, no. 2, pp. 324-329, 2014.

[6] J. M. O. Andrade, A. F. Paraíso, M. V. M. de Oliveira et al., "Resveratrol attenuates hepatic steatosis in high-fat fed mice by decreasing lipogenesis and inflammation," Nutrition, vol. 30, no. 7-8, pp. 915-919, 2014.

[7] M. Azachi, R. Yatuv, A. Katz, Y. Hagay, and A. Danon, "A novel red grape cells complex: health effects and bioavailability of natural resveratrol," International Journal of Food Sciences and Nutrition, vol. 65, no. 7, pp. 848-855, 2014.

[8] S. Heebøll, K. L. Thomsen, S. B. Pedersen, H. Vilstrup, J. George, and H. Grønbæk, "Effects of resveratrol in experimental and clinical non-alcoholic fatty liver disease," World Journal of Hepatology, vol. 6, no. 4, pp. 188-198, 2014.

[9] J. Tian and J. W. Chen, “The application of resveratrol in treating rheumatic disease: a review," Zhongguo Zhong Xi Yi Jie He Za Zhi, vol. 32, no. 12, pp. 1710-1713, 2012.

[10] K. Legg, "Metabolic disease: identifying novel targets of resveratrol," Nature Reviews Drug Discovery, vol. 11, no. 4, p. 273, 2012.

[11] K. Magyar, R. Halmosi, A. Palfi et al., "Cardioprotection by resveratrol: a human clinical trial in patients with stable coronary artery disease," Clinical Hemorheology and Microcirculation, vol. 50, no. 3, pp. 179-187, 2012.

[12] F. Li, Q. Gong, H. Dong, and J. Shi, "Resveratrol, a neuroprotective supplement for Alzheimer's disease," Current Pharmaceutical Design, vol. 18, no. 1, pp. 27-33, 2012.

[13] L. G. Wood, P. A. B. Wark, and M. L. Garg, "Antioxidant and anti-inflammatory effects of resveratrol in airway disease," Antioxidants and Redox Signaling, vol. 13, no. 10, pp. 1535-1548, 2010.

[14] A. Csiszar, "Anti-inflammatory effects of resveratrol: possible role in prevention of age-related cardiovascular disease," Annals of the New York Academy of Sciences, vol. 1215, no. 1, pp. 117-122, 2011.

[15] W. Wang, L. Sun, P. Zhang, J. Song, and W. Liu, "An antiinflammatory cell-free collagen/resveratrol scaffold for repairing osteochondral defects in rabbits," Acta Biomaterialia, vol. 10, no. 12, pp. 4983-4995, 2014.

[16] J. C. Nwachukwu, S. Srinivasan, N. E. Bruno et al., "Resveratrol modulates the inflammatory response via an estrogen receptorsignal integration network," eLife, vol. 3, p. e02057, 2014.

[17] M. C. Saleh, B. J. Connell, and T. M. Saleh, "Resveratrol induced neuroprotection is mediated via both estrogen receptor subtypes, $\mathrm{ER}_{\alpha}$ and $\mathrm{ER}_{\beta}$," Neuroscience Letters, vol. 548, pp. 217221, 2013.

[18] H.-P. Yu, T.-L. Hwang, P.-W. Hsieh, and Y.-T. Lau, "Role of estrogen receptor-dependent upregulation of P38 MAPK/heme oxygenase 1 in resveratrol-mediated attenuation of intestinal injury after trauma-hemorrhage," Shock, vol. 35, no. 5, pp. 517523, 2011.

[19] C. M. Klinge, K. A. Blankenship, K. E. Risinger et al., "Resveratrol and estradiol rapidly activate MAPK signaling through estrogen receptors alpha and beta in endothelial cells," The Journal of Biological Chemistry, vol. 280, no. 9, pp. 7460-7468, 2005.
[20] H.-P. Yu, T.-L. Hwang, T.-L. Hwang, C.-H. Yen, and Y.-T. Lau, "Resveratrol prevents endothelial dysfunction and aortic superoxide production after trauma hemorrhage through estrogen receptor-dependent hemeoxygenase-1 pathway," Critical Care Medicine, vol. 38, no. 4, pp. 1147-1154, 2010.

[21] J. Ren, C. Fan, N. Chen, J. Huang, and Q. Yang, "Resveratrol pretreatment attenuates cerebral ischemic injury by upregulating expression of transcription factor Nrf2 and HO-1 in Rats," Neurochemical Research, vol. 36, no. 12, pp. 2352-2362, 2011.

[22] Y. Zheng, Y. Liu, J. Ge et al., "Resveratrol protects human lens epithelial cells against $\mathrm{H}_{2} \mathrm{O}_{2}$ - induced oxidative stress by increasing catalase, SOD-1, and HO-1 expression," Molecular Vision, vol. 16, pp. 1467-1474, 2010.

[23] N. Tamaki, R. C. Orihuela-Campos, Y. Inagaki, M. Fukui, T. Nagata, and H.-O. Ito, "Resveratrol improves oxidative stress and prevents the progression of periodontitis via the activation of the Sirtl/AMPK and the Nrf2/antioxidant defense pathways in a rat periodontitis model," Free Radical Biology and Medicine, vol. 75, pp. 222-229, 2014.

[24] J. Li, L. Feng, Y. Xing et al., "Radioprotective and antioxidant effect of resveratrol in hippocampus by activating Sirt1," International Journal of Molecular Sciences, vol. 15, no. 4, pp. 59285939, 2014.

[25] Z. Ren, L. Wang, J. Cui et al., "Resveratrol inhibits NF- $\kappa B$ signaling through suppression of p65 and IkappaB kinase activities," Pharmazie, vol. 68, no. 8, pp. 689-694, 2013.

[26] J. Zhang, J. Chen, J. Yang et al., "Resveratrol attenuates oxidative stress induced by balloon injury in the rat carotid artery through actions on the ERK1/2 and NF-kappa B pathway," Cellular Physiology and Biochemistry, vol. 31, no. 2-3, pp. 230-241, 2013.

[27] M. Mokni, S. Hamlaoui, I. Karkouch et al., "Resveratrol provides cardioprotection after ischemia/reperfusion injury via modulation of antioxidant enzyme activities," Iranian Journal of Pharmaceutical Research, vol. 12, no. 4, pp. 867-875, 2013.

[28] H. A. Bagriyanik, N. Ersoy, C. Cetinkaya et al., "The effects of resveratrol on chronic constriction injury of sciatic nerve in rats," Neuroscience Letters, vol. 561, pp. 123-127, 2014.

[29] J. Zhang, N. Tong, Y. Chen, P. Li, S. Yang, and X. Zhao, "Resveratrol protects against vinorelbine-induced vascular endothelial cell injury," Toxicology Mechanisms and Methods, vol. 23, no. 9, pp. 665-671, 2013.

[30] H. X. Zhang, G. L. Duan, C. N. Wang, Y. Q. Zhang, X. Y. Zhu, and Y. J. Liu, "Protective effect of resveratrol against endotoxemia-induced lung injury involves the reduction of oxidative/nitrative stress," Pulmonary Pharmacology \& Therapeutics, vol. 27, no. 2, pp. 150-155, 2014.

[31] A. P. Vin, H. Hu, Y. Zhai et al., "Neuroprotective effect of resveratrol prophylaxis on experimental retinal ischemic injury," Experimental Eye Research, vol. 108, pp. 72-75, 2013.

[32] T. Tunali-Akbay, O. Sehirli, F. Ercan, and G. Sener, "Resveratrol protects against methotrexate-induced hepatic injury in rats," Journal of Pharmacy and Pharmaceutical Sciences, vol. 13, no. 2, pp. 303-310, 2010.

[33] T. de Jesus Soares, R. A. Volpini, H. D. C. Francescato, R. S. Costa, C. G. A. da Silva, and T. M. Coimbra, "Effects of resveratrol on glycerol-induced renal injury," Life Sciences, vol. 81, no. 8, pp. 647-656, 2007.

[34] J. W. Gatson, M. M. Liu, K. Abdelfattah et al., "Resveratrol decreases inflammation in the brain of mice with mild traumatic brain injury," Journal of Trauma and Acute Care Surgery, vol. 74, no. 2, pp. 470-475, 2013. 
[35] L. J. McGhan and D. E. Jaroszewski, "The role of toll-like receptor- 4 in the development of multi-organ failure following traumatic haemorrhagic shock and resuscitation," Injury, vol. 43, no. 2, pp. 129-136, 2012.

[36] D. M. Stein, J. Menaker, K. McQuillan, C. Handley, B. Aarabi, and T. M. Scalea, "Risk factors for organ dysfunction and failure in patients with acute traumatic cervical spinal cord injury," Neurocritical Care, vol. 13, no. 1, pp. 29-39, 2010.

[37] F.-C. Liu, Y.-F. Tsai, and H.-P. Yu, "Sirtinol attenuates trauma hemorrhage-induced hepatic injury through Akt-dependent pathway in rats," Journal of Trauma and Acute Care Surgery, vol. 74, no. 4, pp. 1027-1032, 2013.

[38] Y.-F. Tsai, F.-C. Liu, Y.-T. Lau, and H.-P. Yu, "Role of Aktdependent pathway in resveratrol-mediated cardioprotection after trauma-hemorrhage," Journal of Surgical Research, vol. 176, no. 1, pp. 171-177, 2012.

[39] H.-P. Yu, S.-C. Yang, Y.-T. Lau, and T.-L. Hwang, "Role of Aktdependent up-regulation of hemeoxygenase-1 in resveratrolmediated attenuation of hepatic injury after trauma hemorrhage," Surgery, vol. 148, no. 1, pp. 103-109, 2010.

[40] C.-T. Wu, H.-P. Yu, C.-Y. Chung, Y.-T. Lau, and S.-K. Liao, "Attenuation of lung inflammation and pro-inflammatory cytokine production by resveratrol following traumahemorrhage," The Chinese Journal of Physiology, vol. 51, no. 6, pp. 363-368, 2008.

[41] H.-P. Yu, J.-C. Hsu, T.-L. Hwang, C.-H. Yen, and Y.-T. Lau, "Resveratrol attenuates hepatic injury after trauma-hemorrhage via estrogen receptor-related pathway," Shock, vol. 30, no. 3, pp. 324-328, 2008.

[42] F.-C. Liu, Y.-J. Day, C.-H. Liao, J.-T. Liou, C.-C. Mao, and H.P. Yu, "Hemeoxygenase-1 upregulation is critical for sirtinolmediated attenuation of lung injury after trauma-hemorrhage in a rodent model," Anesthesia \& Analgesia, vol. 108, no. 6, pp. 1855-1861, 2009.

[43] H.-P. Yu, M. A. Choudhry, T. Shimizu et al., "Mechanism of the salutary effects of flutamide on intestinal myeloperoxidase activity following trauma-hemorrhage: up-regulation of estrogen receptor- $\beta$-dependent HO-1," Journal of Leukocyte Biology, vol. 79, no. 2, pp. 277-284, 2006.

[44] D. I. Sonnier, A. T. Makley, L. A. W. Friend, S. R. Bailey, A. B. Lentsch, and T. A. Pritts, "Hemorrhagic shock induces a proinflammatory milieu in the gut lumen," Journal of Surgical Research, vol. 170, no. 2, pp. 272-279, 2011.

[45] T. Shimizu, H.-P. Yu, Y.-C. Hsieh et al., "Flutamide attenuates pro-inflammatory cytokine production and hepatic injury following trauma-hemorrhage via estrogen receptor-related pathway," Annals of Surgery, vol. 245, no. 2, pp. 297-304, 2007.

[46] T. Suzuki, T. Shimizu, H.-P. Yu et al., "Tissue compartmentspecific role of estrogen receptor subtypes in immune cell cytokine production following trauma-hemorrhage," Journal of Applied Physiology, vol. 102, no. 1, pp. 163-168, 2007.

[47] H.-P. Yu, T. Shimizu, Y.-C. Hsieh et al., “Tissue-specific expression of estrogen receptors and their role in the regulation of neutrophil infiltration in various organs following traumahemorrhage," Journal of Leukocyte Biology, vol. 79, no. 5, pp. 963-970, 2006.

[48] F.-C. Liu, H.-P. Yu, T.-L. Hwang, and Y.-F. Tsai, "Protective effect of tropisetron on rodent hepatic injury after trauma-hemorrhagic shock through P38 MAPK-dependent hemeoxygenase-1 expression," PLoS ONE, vol. 7, no. 12, Article ID e53203, 2012.
[49] F.-C. Liu, Y.-J. Day, J.-T. Liou, Y.-T. Lau, and H.-P. Yu, "Sirtinol attenuates hepatic injury and pro-inflammatory cytokine production following trauma-hemorrhage in male SpragueDawley rats," Acta Anaesthesiologica Scandinavica, vol. 52, no. 5, pp. 635-640, 2008.

[50] H.-P. Yu, P.-W. Hsieh, Y.-J. Chang, P.-J. Chung, L.-M. Kuo, and T.-L. Hwang, "DSM-RX78, a new phosphodiesterase inhibitor, suppresses superoxide anion production in activated human neutrophils and attenuates hemorrhagic shock-induced lung injury in rats," Biochemical Pharmacology, vol. 78, no. 8, pp. 983992, 2009.

[51] H.-P. Yu, S. Yang, Y.-C. Hsieh, M. A. Choudhry, K. I. Bland, and I. H. Chaudry, "Maintenance of lung myeloperoxidase activity in proestrus females after trauma-hemorrhage: upregulation of heme oxygenase-1," The American Journal of Physiology-Lung Cellular and Molecular Physiology, vol. 291, no. 3, pp. L400L406, 2006.

[52] S. D. Dayal, G. Haskó, Q. Lu et al., "Trauma/hemorrhagic shock mesenteric lymph upregulates adhesion molecule expression and IL-6 production in human umbilical vein endothelial cells," Shock, vol. 17, no. 6, pp. 491-495, 2002.

[53] R. Yang, X. Han, T. Uchiyama et al., "IL-6 is essential for development of gut barrier dysfunction after hemorrhagic shock and resuscitation in mice," The American Journal of Physiology: Gastrointestinal and Liver Physiology, vol. 285, no. 3, pp. G621-G629, 2003.

[54] Z. H. Meng, K. Dyer, T. R. Billiar, and D. J. Tweardy, "Essential role for IL-6 in postresuscitation inflammation in hemorrhagic shock," American Journal of Physiology-Cell Physiology, vol. 280, no. 2, pp. C343-C351, 2001.

[55] T. Suzuki, T. Shimizu, H.-P. Yu et al., "Estrogen receptor-alpha predominantly mediates the salutary effects of 17beta-estradiol on splenic macrophages following trauma-hemorrhage," The American Journal of Physiology: Cell Physiology, vol. 293, no. 3, pp. C978-C984, 2007.

[56] H.-P. Yu, S.-T. Pang, and I. H. Chaudry, "Hepatic gene expression patterns following trauma-hemorrhage: effect of posttreatment with estrogen," Shock, vol. 39, no. 1, pp. 77-82, 2013.

[57] H. Sebai, M. Sani, M. T. Yacoubi, E. Aouani, N. GhanemBoughanmi, and M. Ben-Attia, "Resveratrol, a red wine polyphenol, attenuates lipopolysaccharide-induced oxidative stress in rat liver," Ecotoxicology and Environmental Safety, vol. 73, no. 5, pp. 1078-1083, 2010.

[58] M. A. Choudhry, K. I. Bland, and I. H. Chaudry, "Trauma and immune response-effect of gender differences," Injury, vol. 38, no. 12, pp. 1382-1391, 2007.

[59] M. A. Choudhry, M. G. Schwacha, W. J. Hubbard et al., "Gender differences in acute response to trauma-hemorrhage," Shock, vol. 24, no. 1, pp. 101-106, 2005.

[60] T. Shimizu, H.-P. Yu, T. Suzuki et al., "The role of estrogen receptor subtypes in ameliorating hepatic injury following trauma-hemorrhage," Journal of Hepatology, vol. 46, no. 6, pp. 1047-1054, 2007

[61] T. Suzuki, T. Shimizu, H.-P. Yu, Y.-C. Hsieh, M. A. Choudhry, and I. H. Chaudry, "Salutary effects of 17beta-estradiol on T-cell signaling and cytokine production after trauma-hemorrhage are mediated primarily via estrogen receptor-alpha," The American Journal of Physiology: Cell Physiology, vol. 292, no. 6, pp. C2103-C2111, 2007.

[62] H.-P. Yu and I. H. Chaudry, "The role of estrogen and receptor agonists in maintaining organ function after traumahemorrhage," Shock, vol. 31, no. 3, pp. 227-237, 2009. 
[63] H. P. Yu, Y. C. Hsieh, T. Suzuki et al., "Salutary effects of estrogen receptor- $\beta$ agonist on lung injury after trauma-hemorrhage," The American Journal of Physiology-Lung Cellular and Molecular Physiology, vol. 290, no. 5, pp. L1004-L1009, 2006.

[64] H. P. Yu, Y. C. Hsieh, T. Suzuki et al., "The PI3K/Akt pathway mediates the nongenomic cardioprotective effects of estrogen following trauma-hemorrhage," Annals of Surgery, vol. 245, no. 5, pp. 971-977, 2007.

[65] A. A. Elmarakby, J. Faulkner, B. Baban, and J. C. Sullivan, "Induction of hemeoxygenase-1 reduces renal oxidative stress and inflammation in diabetic spontaneously hypertensive rats," International Journal of Hypertension, vol. 2012, Article ID 957235, 11 pages, 2012.

[66] A. A. Elmarakby, J. Faulkner, S. P. Posey, and J. C. Sullivan, "Induction of hemeoxygenase-1 attenuates the hypertension and renal inflammation in spontaneously hypertensive rats," Pharmacological Research, vol. 62, no. 5, pp. 400-407, 2010.

[67] J.-T. Hsu, W.-H. Kan, C.-H. Hsieh, M. A. Choudhry, K. I. Bland, and I. H. Chaudry, "Mechanism of salutary effects of estrogen on cardiac function following trauma-hemorrhage: akt-dependent HO-1 up-regulation," Critical Care Medicine, vol. 37, no. 8, pp. 2338-2344, 2009.

[68] J.-T. Hsu, W. H. Kan, C.-H. Hsieh et al., "Mechanism of estrogen-mediated attenuation of hepatic injury following trauma-hemorrhage: Akt-dependent HO-1 up-regulation," Journal of Leukocyte Biology, vol. 82, no. 4, pp. 1019-1026, 2007.

[69] J.-T. Hsu, H.-C. Yeh, T.-H. Chen et al., "Role of Akt/HO-1 pathway in estrogen-mediated attenuation of trauma-hemorrhageinduced lung injury," Journal of Surgical Research, vol. 182, no. 2, pp. 319-325, 2013.

[70] F.-C. Liu, T.-L. Hwang, Y.-T. Lau, and H.-P. Yu, "Mechanism of salutary effects of astringinin on rodent hepatic injury following trauma-hemorrhage: Akt-dependent hemeoxygenase-1 signaling pathways," PLoS ONE, vol. 6, no. 10, Article ID e25907, 2011.

[71] B. Chen, J. Xue, X. Meng, J. L. Slutzky, A. E. Calvert, and L. G. Chicoine, "Resveratrol prevents hypoxia-induced arginase II expression and proliferation of human pulmonary artery smooth muscle cells via Akt-dependent signaling," The American Journal of Physiology -Lung Cellular and Molecular Physiology, vol. 307, no. 4, pp. L317-L325, 2014.

[72] F. Simão, A. Matté, A. S. Pagnussat, C. A. Netto, and C. G. Salbego, "Resveratrol prevents CA1 neurons against ischemic injury by parallel modulation of both GSK-3beta and CREB through PI3-K/Akt pathways," European Journal of Neuroscience, vol. 36, no. 7, pp. 2899-2905, 2012.

[73] R. D. Powell, J. H. Swet, K. L. Kennedy, T. T. Huynh, I. H. McKillop, and S. L. Evans, "Resveratrol attenuates hypoxic injury in a primary hepatocyte model of hemorrhagic shock and resuscitation," Journal of Trauma and Acute Care Surgery, vol. 76, no. 2, pp. 409-417, 2014.

[74] F.-C. Liu, F.-W. Liu, and H.-P. Yu, "Ondansetron attenuates hepatic injury via p38 MAPK-dependent pathway in a rat haemorrhagic shock model," Resuscitation, vol. 82, no. 3, pp. 335-340, 2011.

[75] J.-T. Hsu, W.-H. Kan, C.-H. Hsieh et al., "Mechanism of estrogen-mediated intestinal protection following traumahemorrhage: p38 MAPK-dependent upregulation of HO-1," The American Journal of Physiology-Regulatory Integrative and Comparative Physiology, vol. 294, no. 6, pp. R1825-R1831, 2008.

[76] X. W. Liu, E. F. Ji, P. He, R. X. Xing, B. X. Tian, and X. D. $\mathrm{Li}$, "Protective effects of the p38 MAPK inhibitor SB203580 on
NMDA-induced injury in primary cerebral cortical neurons," Molecular Medicine Reports, vol. 10, no. 4, pp. 1942-1948, 2014.

[77] S. Wang, Q. Huang, J. Guo et al., "Local thermal injury induces general endothelial cell contraction through p38 MAP kinase activation," Acta Pathologica, Microbiologica et Immunologica Scandinavica, vol. 122, no. 9, pp. 832-841, 2014.

[78] J. Ma, Y.-Q. Fang, A.-M. Gu, F.-F. Wang, S. Zhang, and K.-C. Li, "P38 activation is more important than ERK activation in lung injury induced by prolonged hyperbaric oxygen," Undersea and Hyperbaric Medicine, vol. 40, no. 4, pp. 313-318, 2013.

[79] D. E. Shifflett, S. L. Jones, A. J. Moeser, and A. T. Blikslager, "Mitogen-activated protein kinases regulate COX-2 and mucosal recovery in ischemic-injured porcine ileum," The American Journal of Physiology: Gastrointestinal and Liver Physiology, vol. 286, no. 6, pp. G906-G913, 2004.

[80] L. Aoudjit, M. Stanciu, H. Li, S. Lemay, and T. Takano, “p38 mitogen-activated protein kinase protects glomerular epithelial cells from complement-mediated cell injury," The American Journal of Physiology-Renal Physiology, vol. 285, no. 4, pp. F765-F774, 2003.

[81] S. Sánchez-Fidalgo, A. Cárdeno, I. Villegas, E. Talero, and C. A. de la Lastra, "Dietary supplementation of resveratrol attenuates chronic colonic inflammation in mice," European Journal of Pharmacology, vol. 633, no. 1-3, pp. 78-84, 2010.

[82] X. C. Lv and H. Y. Zhou, "Resveratrol protects H9c2 embryonic rat heart derived cells from oxidative stress by inducing autophagy: role of p38 mitogen-activated protein kinase," Canadian Journal of Physiology and Pharmacology, vol. 90, no. 5, pp. 655-662, 2012.

[83] D. Babu, S. J. Soenen, K. Raemdonck et al., “TNF$\alpha /$ cycloheximide-induced oxidative stress and apoptosis in murine intestinal epithelial MODE-K cells," Current Pharmaceutical Design, vol. 18, no. 28, pp. 4414-4425, 2012.

[84] M. Mokni, F. Limam, S. Elkahoui, M. Amri, and E. Aouani, "Strong cardioprotective effect of resveratrol, a red wine polyphenol, on isolated rat hearts after ischemia/reperfusion injury," Archives of Biochemistry and Biophysics, vol. 457, no. 1, pp. 1-6, 2007.

[85] L.-M. Hung, M.-J. Su, and J.-K. Chen, "Resveratrol protects myocardial ischemia-reperfusion injury through both NOdependent and NO-independent mechanisms," Free Radical Biology and Medicine, vol. 36, no. 6, pp. 774-781, 2004.

[86] B. Jian, S. Yang, I. H. Chaudry, and R. Raju, "Resveratrol improves cardiac contractility following trauma-hemorrhage by modulating Sirtl," Molecular Medicine, vol. 18, no. 2, pp. 209214, 2012.

[87] X. Jiang, C. Ai, E. Shi, Y. Nakajima, and H. Ma, "Neuroprotection against spinal cord ischemia-reperfusion injury induced by different ischemic postconditioning methods: roles of phosphatidylinositol 3-kinase-akt and extracellular signalregulated kinase," Anesthesiology, vol. 111, no. 6, pp. 1197-1205, 2009.

[88] L. Lv, Q. Meng, J. Xu, J. Gong, Y. Cheng, and S. Jiang, "Ligustrazine attenuates myocardial ischemia reperfusion injury in rats by activating the phosphatidylinositol 3-kinase/Akt pathway," Annals of Clinical and Laboratory Science, vol. 42, no. 2, pp. 198-202, 2012.

[89] G. Schabbauer, M. Tencati, B. Pedersen, R. Pawlinski, and N. Mackman, "PI3K-Akt pathway suppresses coagulation and inflammation in endotoxemic mice," Arteriosclerosis, Thrombosis, and Vascular Biology, vol. 24, no. 10, pp. 1963-1969, 2004. 
[90] W.-P. Fung-Leung, "Phosphoinositide 3-kinase delta (PI3K $\delta)$ in leukocyte signaling and function," Cellular Signalling, vol. 23, no. 4, pp. 603-608, 2011.

[91] H. He, F. X. Yu, C. Sun, and Y. Luo, "CBP/p300 and SIRT1 are involved in transcriptional regulation of S-phase specific histone genes," PLoS ONE, vol. 6, no. 7, Article ID e22088, 2011.

[92] K. Pruitt, R. L. Zinn, J. E. Ohm et al., "Inhibition of SIRT1 reactivates silenced cancer genes without loss of promoter DNA hypermethylation," PLoS Genetics, vol. 2, no. 3, article e40, 2006.

[93] Y.-G. Li, W. Zhu, J.-P. Tao et al., "Resveratrol protects cardiomyocytes from oxidative stress through SIRT1 and mitochondrial biogenesis signaling pathways," Biochemical and Biophysical Research Communications, vol. 438, no. 2, pp. 270-276, 2013.

[94] B. Jian, S. Yang, I. H. Chaudry, and R. Raju, "Resveratrol restores sirtuin 1 (SIRT1) activity and pyruvate dehydrogenase kinase 1 (PDK1) expression after hemorrhagic injury in a rat model," Molecular Medicine, vol. 20, no. 1, pp. 10-16, 2014.

[95] H.-P. Yu, P.-W. Lui, T.-L. Hwang, C.-H. Yen, and Y.-T. Lau, "Propofol improves endothelial dysfunction and attenuates vascular superoxide production in septic rats," Critical Care Medicine, vol. 34, no. 2, pp. 453-460, 2006.

[96] Z. F. Ba, J. F. Kuebler, L. W. Rue III, K. I. Bland, P. Wang, and I. H. Chaudry, "Gender dimorphic tissue perfusion response after acute hemorrhage and resuscitation: role of vascular endothelial cell function," American Journal of Physiology: Heart and Circulatory Physiology, vol. 284, no. 6, pp. H2162-H2169, 2003.

[97] P. Wang, Z. F. Ba, and I. H. Chaudry, "Endothelial cell dysfunction occurs very early following trauma- hemorrhage and persists despite fluid resuscitation," The American Journal of Physiology: Heart and Circulatory Physiology, vol. 265, no. 3, part 2, pp. H973-H979, 1993.

[98] A. C. Montezano and R. M. Touyz, "Reactive oxygen species and endothelial function-role of nitric oxide synthase uncoupling and nox family nicotinamide adenine dinucleotide phosphate oxidases," Basic \& Clinical Pharmacology and Toxicology, vol. 110, no. 1, pp. 87-94, 2012.

[99] P. Orsu, B. V. S. N. Murthy, and A. Akula, "Cerebroprotective potential of resveratrol through anti-oxidant and antiinflammatory mechanisms in rats," Journal of Neural Transmission, vol. 120, no. 8, pp. 1217-1223, 2013.

[100] S. Bo, G. Ciccone, A. Castiglione et al., "Anti-inflammatory and antioxidant effects of resveratrol in healthy smokers a randomized, double-blind, placebo-controlled, cross-over trial," Current Medicinal Chemistry, vol. 20, no. 10, pp. 1323-1331, 2013.

[101] G. Petrovski, N. Gurusamy, and D. K. Das, "Resveratrol in cardiovascular health and disease," Annals of the New York Academy of Sciences, vol. 1215, no. 1, pp. 22-33, 2011.

[102] H. Z. Toklu, Ö. Şehirli, M. Erşahin et al., "Resveratrol improves cardiovascular function and reduces oxidative organ damage in the renal, cardiovascular and cerebral tissues of two-kidney, one-clip hypertensive rats," Journal of Pharmacy and Pharmacology, vol. 62, no. 12, pp. 1784-1793, 2010.

[103] X. Cong, Y. Li, N. Lu et al., "Resveratrol attenuates the inflammatory reaction induced by ischemia/reperfusion in the rat heart," Molecular Medicine Reports, vol. 9, no. 6, pp. 2528-2532, 2014.

[104] Y. Tang, J. Xu, W. Qu et al., "Resveratrol reduces vascular cell senescence through attenuation of oxidative stress by SIRT1/NADPH oxidase-dependent mechanisms," The Journal of Nutritional Biochemistry, vol. 23, no. 11, pp. 1410-1416, 2012.
[105] S.-E. Chow, Y.-C. Hshu, J.-S. Wang, and J.-K. Chen, "Resveratrol attenuates oxLDL-stimulated NADPH oxidase activity and protects endothelial cells from oxidative functional damages," Journal of Applied Physiology, vol. 102, no. 4, pp. 1520-1527, 2007.

[106] J. Wang, X. Hu, and H. Jiang, "Nrf-2-HO-1-HMGB1 axis: an important therapeutic approach for protection against myocardial ischemia and reperfusion injury," International Journal of Cardiology, vol. 172, no. 1, pp. 223-224, 2014.

[107] S. Tsuchihashi, Y. Zhai, C. Fondevila, R. W. Busuttil, and J. W. Kupiec-Weglinski, "HO-1 upregulation suppresses type 1 IFN pathway in hepatic ischemia/reperfusion injury," Transplantation Proceedings, vol. 37, no. 4, pp. 1677-1678, 2005. 


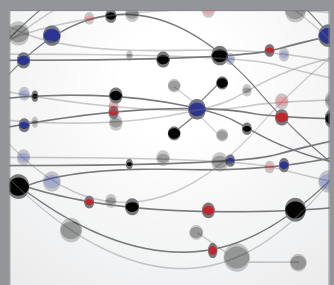

The Scientific World Journal
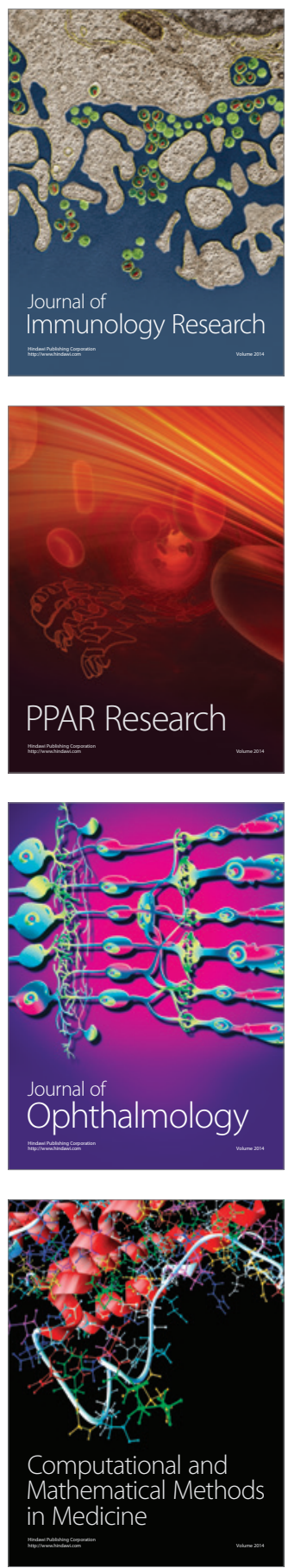

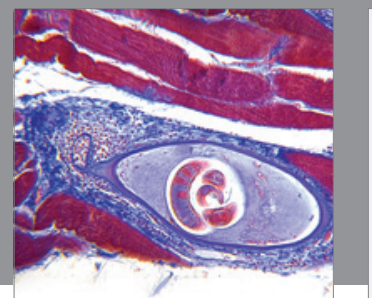

Gastroenterology

Research and Practice
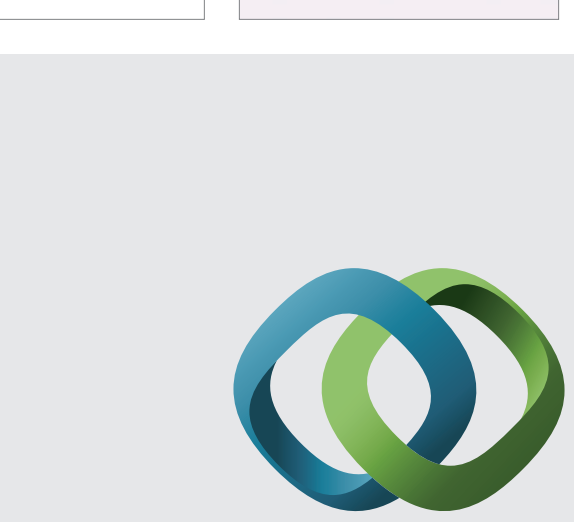

\section{Hindawi}

Submit your manuscripts at

http://www.hindawi.com
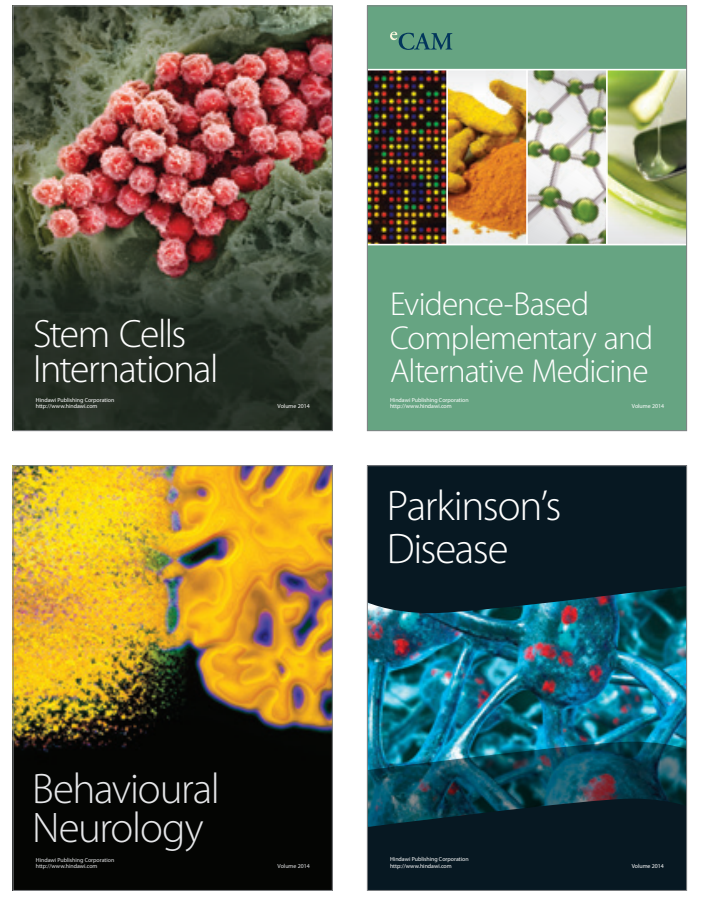
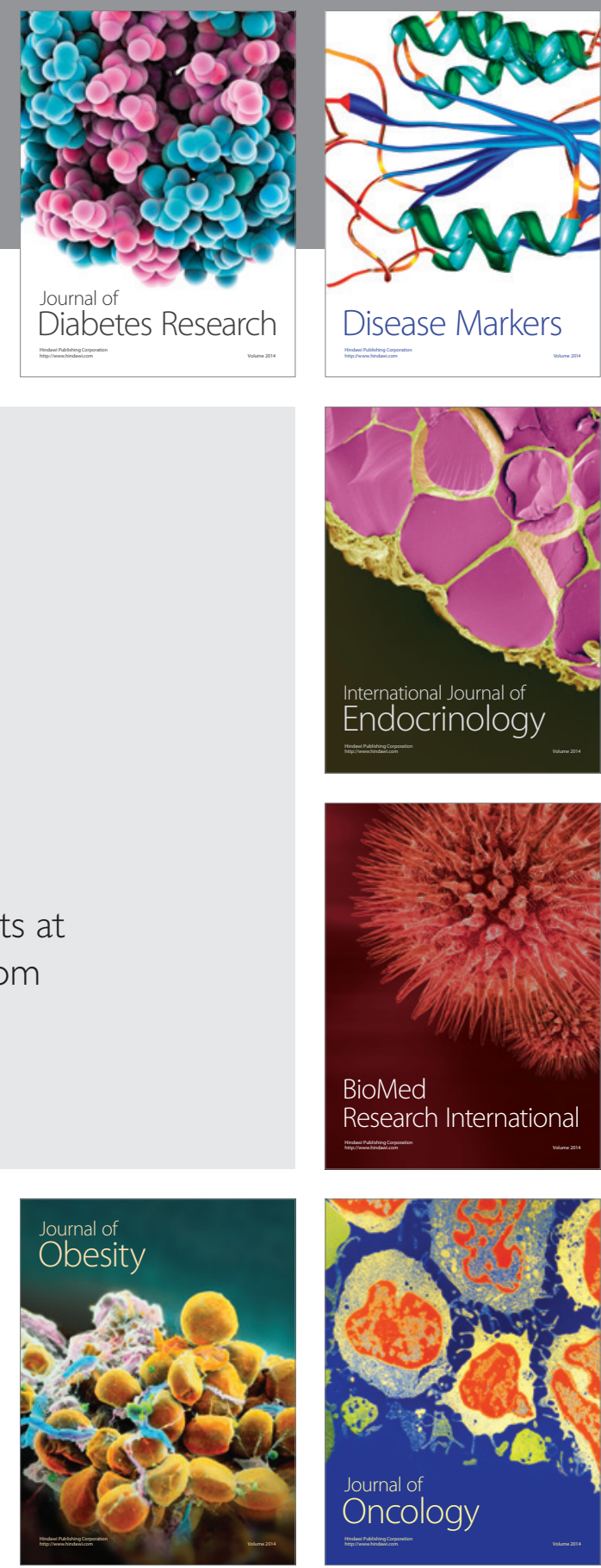

Disease Markers
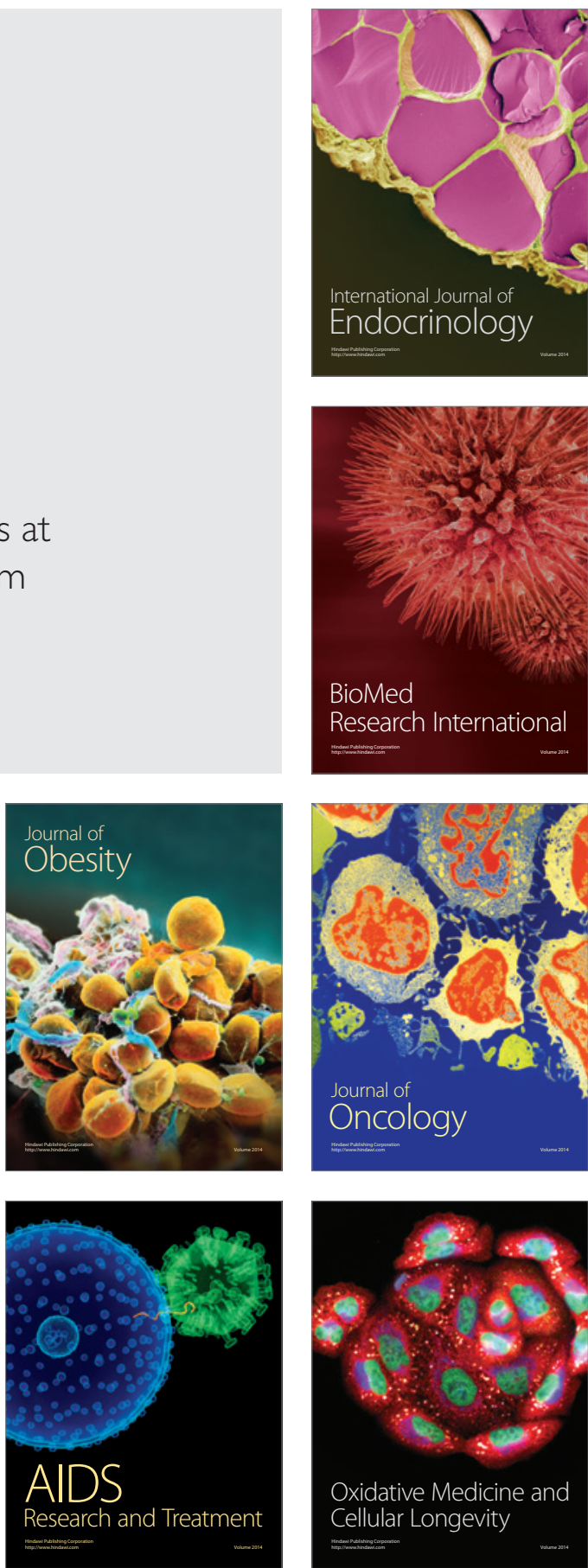